Journal of Teacher Education for Sustainability, vol. 17, no. 1, pp. 23-34, 2015

\title{
Digital Citizenship in the Afterschool Space: Implications for Education for Sustainable Development
}

\author{
Patrick Howard \\ Cape Breton University, Canada
}

\begin{abstract}
Education for sustainable development (ESD) challenges traditional curricula and formal schooling in important ways. ESD requires systemic thinking, interdisciplinarity and is strengthened through the contributions of all disciplines. As with any transformative societal and technological shift, new questions arise when educators are required to venture into unchartered waters. Research has led to some interesting findings concerning digital literacies in the K-12 classroom. One finding is that a great deal of digital media learning is happening outside the traditional classroom space and is taking place in the afterschool space (Prensky, 2010). Understanding the nature of learning in the afterschool space and bridging the current divide between formal schooling and the learning happening online is critical to the establishment of core ESD values and skills, namely ethical online communities and the development of respectful, tolerant global digital citizens.
\end{abstract}

Keywords: digital media, education for sustainable development, New Literacies, digital citizenship, teacher education

At the core of education for sustainable development (ESD) is the understanding that the education offered by $19^{\text {th }}$ and $20^{\text {th }}$ century formal, traditional schooling is not adequate for the $21^{\text {st }}$ century. Children and young adults are required to develop skills and competencies that have been largely excluded from the curricula of traditional schooling in the last century. A recent report on the future of education, the Equinox Blueprint: Learning 2030 prepared by the Waterloo Global Science Initiative (2014) states,

Students will need to learn how to learn - how to gather and synthesize information from many sources, how to think critically about it, and how to fashion creative responses to problems and challenges. In addition to reading, writing and numeracy, students will need to acquire new literacies such as data visualization and analysis, search literacy and visual literacy (Brooks \& Holmes, 2014, p. 10). 
Issues of climate change and water, energy and food challenges require innovative thinking from people who can work collaboratively across disciplines and national boundaries. They will need to learn how to be creative and how to foster and develop their innate creativity. Literacy studies and the language arts will be at the core of the endeavor to cultivate the skills, values and creativity necessary to adapt and adopt New Literacies.

As an educator responsible for the preparation of K-12 literacy and language arts teachers, I am interested in how new technologies are radically changing the types of texts people create and interpret. Digital technologies are posing challenges for literacy educators and disrupting the entire field of literacy education in interesting ways. As with any transformative societal shift, new questions arise, and educators are required to venture into unchartered waters. There are those who believe incorporating digital literacies including visual, audio, multimodal, multimedia literacy overwhelms the language arts. In contrast, there are those who advocate for a radical re-formulation of the discipline to include New Literacies (Burn \& Nixon, 2005). The significance of New Literacies reaches beyond technical skills and has more to do with how it enables people to build and participate in literacy practices that involve different kinds of values, sensibilities, norms and procedures from those that characterise conventional literacies (Doering, Beach, \& O’Brien, 2007). Specifically, New Literacies incorporate the values and pedagogies of collaboration and participation, the harnessing of collective intelligence, the building of relationships and the de-centering of authorship. ESD provides a context whereby literacy educators can bridge old binaries that divide and position literacy and language arts pedagogy and content on one side and technology on another.

My research is built on the premise that pre-service teachers of literacy and the language arts should be prepared to facilitate more complex, inclusive approaches to teaching children how to compose texts that reflect the New Literacies as new practices. As future teachers of writing, pre-service education students engaged in creating multimodal, multimedia texts during their teacher education will be better prepared to facilitate the design and production of multimodal, multimedia texts. The premise is that the experience of creating digital texts will allow the children that pre-service teachers will one day teach to draw on both social and genre knowledge in the creation of original texts and to move across digital modes. This line of inquiry has led to some interesting findings and new questions concerning not only digital literacies in the K-12 classroom, but also the place for digital literacies in the pre-service teacher education classroom.

Erasing divisions between literacy and technology and understanding the relationship between traditional and digital texts means embracing evolving definitions of texts. Recently, I conducted research designed to immerse pre-service English education students in the creation of multimodal, multimedia texts as part of a digital composing workshop (Howard, 2014). A growing number of researchers are exploring the media practices and emerging digital literacies of children and youth (Barrell \& Hammett, 2002; Knobel \& Lankshear, 2007; Mills, 2010), yet few studies have inquired into the composing processes of pre-service literacy teachers and the pedagogical possibilities to emerge from immersing prospective literacy teachers in constructing multimodal, multimedia texts (Buck, 2012; Robertson, Hughes, \& Smith, 2012). My research set out to determine what happens when English educators provide authentic, engaging opportunities for pre-service literacy teachers to learn about and through multimedia, multimodal digital technologies. As is so often the case, the research project raised other questions and 
pointed in unanticipated directions. The experience of two pre-service English education teachers, Kyle and Anna (pseudonyms), in particular, raised interesting and potentially troubling questions about the experience of creating texts in online spaces. Simply saying students require a broad set of $21^{\text {st }}$ century skills, attitudes, beliefs, knowledge that includes communication, critical thinking, problem solving combined with creativity and innovation is one thing; moving the current system, and preparing teachers and students for a rapidly changing world and unprecedented future challenges is another. Such a transformation is complex and requires understanding the shifts that are taking place in schools currently and capitalising on the emergence of new technologies and new literacies to advance the ESD agenda. Change is occurring in traditional, formal schooling. Students in the West and in many countries around the world are living media saturated lives. Teachers do not have to "teach" students to use new technologies. However, engaging students in authentic, relevant tasks co-designed with them to enhance their skills, their understanding of global realities and their collaborative relationships to complete important tasks that contribute to community requires an understanding of the basic precepts of ESD. This is critical if we want to shift the educational paradigm towards sustainability and well-being.

In the next section, the experience of two pre-service teachers is described to demonstrate the complexity in preparing teachers to facilitate classrooms that fully and authentically embrace New Literacies. Creating texts in online spaces requires not only technological content knowledge, but also a nuanced understanding of how new media composition forms, and the reality of diverse, distant audiences for these compositions, creates real opportunity and real challenge. Let's take a closer look at the pre-service teachers, Kyle and Anna.

\section{The Afterschool Space}

Kyle embodied the observation that while productive, authentic, meaningful learning is happening in young people's lives; it is just not happening that often in formal, traditional classrooms. More often than not this type of learning is occurring in what Prensky (2010) calls the afterschool space. It is a term used to describe the increasing prevalence of informal learning through peers, the Internet, YouTube, cell phones and other emerging technologies and online software applications or apps. It is in the afterschool space that students are in control of their own learning, independently following their own interests and passions. Kyle, a 23 year old pre-service teacher, created a stop motion video as a multimedia text as a part of the research project. Kyle admits that his previous digital projects were never considered "texts". He said, "I did them on my own time out of my interest in technology. I didn't consider them texts, but a separate entity." Kyle revealed that his technical skills in stop motion animation were partially self-taught, yet he developed the skills mainly in DIY online spaces, viewing YouTube videos, talking to friends and watching tutorials online.

What can be made of this apparent division between the classroom and the learning happening informally in young people's lives? Kyle's experience creating multimedia texts in an online environment outside the boundaries of traditional schooling, or what Prensky (2010) calls the afterschool space, leads me to ask the questions: What is the meaning of the afterschool space in the lives of young people as it relates to multimedia literacies? What kind of learning is happening there? How do students experience the 
space? What are the connections between the afterschool space and the formal classroom? To re-orient education for the values of sustainability, how can the two spaces be integrated? Should they be integrated? Students are spending increasing amounts of time in online spaces outside the traditional classroom. It is estimated that $64 \%$ of teens engage in content creation in online participatory spaces (Lankshear \& Knobel, 2007) Students are immersed in what Jenkins (2006) has termed “participatory culture". Participatory culture shifts the focus from individual expression to community involvement, and these online communities to which students belong provide strong incentives for creative expressions and active participation.

Scholars debate the nature of the online community or cyber community. Some argue the 'cyber community' is based on connectivity and belonging-ness, sharing personal thoughts and opinions, sharing passions and deep interests, creating a sense of ownership and rituals of practice (Thomas, 2008). Some media scholars even go as far to say that the experience of being "wired" and connected to others sharing what matters most to you often results in the fusion of technology and personal investment in online relationships which results in those same online relationships being integral to a young person's identity. So much so that the experience of not being connected or wired leads to young people not feeling like "themselves". What are the implications for the traditional classroom where students may be equipped with mediocre or, in many cases, no technology? According to Thomas (2008), "at best it leaves them bored or somewhat frustrated, at worst it leaves them incapacitated, disempowered and unenthused, powerfully affecting their social futures" (p. 678). This relates to a major challenge that ESD hopes to address, namely the intellectual disengagement of students in traditional schooling. Hopkins (2013) reports, "A Canadian Education Association survey of secondary students showed that by grade 12 , only $37 \%$ of the students felt intellectually engaged in school (p. 25). ESD approaches that channel authentic, relevant, real world learning may go along way to addressing this issue.

Other scholars contest the notion of "membership" and "community" as they relate to online spaces. DeVane (2012) uses the notion of affinity spaces to understand how identity formation happens online. According to Gee (2004), affinity spaces are social spaces in which people affiliate and learn on the basis of shared interest and endeavour. DeVane posits that the notion of community does not capture all that happens in affinity spaces. The new focus is "not centered on a social groups' constitution or boundaries of membership, but rather on the activity undertaken by learners" (DeVane, 2012, p. 166). Online affinity spaces offer their participants the opportunity to participate pseudonymously or even anonymously, which impacts the traditional notions of community and belonging. The population of these groups can range into the thousands, which also makes the idea of membership more complicated in many respects. Still, affinity spaces are sites where social processes like collaboration, competition, apprenticeship, affiliation and exclusion greatly affect how people learn and participate.

Gee (2004) contrasts the learning in an affinity space with that of the traditional classroom. Classrooms tend to reward individual knowledge, not distributed knowledge. They do not often encourage students to network with each other and rarely do so beyond the physical classroom space using various tools and technologies. Classrooms tend to constrain and strictly control where students gain knowledge. They rarely honour skills or knowledge that falls outside a narrow academic domain. Kyle shared his frustration with the interviewer saying his creation of a digital media text as part of the 
research project was the first time in his students' experience that such an activity was valued and did not directly compete for time with more traditional schoolbased learning activities.

Similarly, Abrams, Gerber and Burgess (2012) describe students' experiences that indicate disillusionment with formal schooling due to academic struggle and social exclusion. The researchers, through unique case studies of secondary school students, demonstrate complex learning and literacy practices happening predominately through game play occurring in the afterschool space. They highlighted the experience of Robbie, a struggling learner in the classroom immersed in the online experience of playing battlefield 1942, a World War 2 first person shooter game. Robbie's game play was the impetus for him to access other websites, podcasts, traditional encyclopedias, the History Channel programming to learn tactics to enhance his game play. The researchers add that "in addition to discovering information through reading and interpreting written text, images, sounds, movements, Robbie took risks in a safe, self-chosen, virtual environment" (Abrams et al., 2012, p. 97). He even obtained a Croatian-English dictionary to better understand his Croatian teammates in the Battlefield 1942 game. However, Robbie never thought of his gaming as being related to learning or had any connection to his traditional academic work.

Gee (2004) challenges a teacher to consider the spaces in which young people are spending more of their time and are arguably experiencing a powerful vision of learning, affiliation and identity. In the afterschool spaces, learning becomes a personal and social journey in which the students grow in proficiency most often doing things they enjoy and are passionate about with like-minded others. The challenge for educators is to honestly evaluate traditional models of teaching and assessment that fall far short of the engagement and the daily demands of our digitally charged world.

\section{Text Creation in Affinity Spaces}

The second student is Anna - an enthusiastic 23-year-old - came to the teacher education programme from a Bachelor of Arts degree majoring in English and drama. She said, "I have been drawing with Photoshop since I was young, but I haven't done it for years. I had lost my connection with digital art, and I used this project to re-connect with an old passion." Anna fully embraces the expanded notion of text to include multimedia digital texts. Her undergraduate English degree included "a class where we studied paintings and poetry together (from the same historical period), in another class we studied film and in a Gothic literature class we studied film and comic books". As part of the research project, Anna chose to respond to the poem "Valentine" by Carol Ann Duffy through a digitally constructed visual representation. Anna created the digital image using the online affinity site DeviantArt.com The site describes itself as, "a community destination... a platform that allows emerging and established artists to exhibit, promote and share their works within a peer community dedicated to the arts..." (about.DeviantArt.com).

The rise of digital culture is remaking reading and writing as central to many spheres of young people's lives, including work, school, recreation and communication. New and innovative technology has created changes and challenges in formal education while suggesting new ways of teaching and learning, including how literacy educators teach writing (Swenson, Rozema, Young, McGrail, \& Whitin, 2006). Traditionally, 
writing and writing methodologies regarded computer technologies as tools useful for word processing capability (Soven, 1999). Popular and influential writing methodology texts published in the last two decades view the relationship between computers and writing for, primarily, their word processing capability whereby student writers "mess around more with text-saving, rearranging, adding, deleting" (Atwell, 1993, p. 102). The widespread introduction of word processing did not challenge our notions of textuality and literacy because the technology was seen as directly related to preparing documents for printing on paper (Dobson \& Willinsky, 2009).

An analysis of the sophisticated level of response required to create the digital media text goes beyond the scope of this paper. But it should be said Anna was able to read the poem for personal connections and then combine strategies, resources and technologies to formulate a response. Choosing the form allowed her to explore, clarify and reflect on her thoughts and prior learning while using her imagination. Creating the text while drawing on a global community of like-minded individuals to offer feedback in a highly generative, participatory environment provides a learning experience that embodies the pull approach to learning rather than the traditional "push" approach. Anna's capabilities and engagement are fostered and develop in such a participatory community as she is helped to learn and also to innovate by pursuing paths of learning tailored specifically to her needs.

The afterschool space is central to the shifting landscape of literacy education due to the increasing availability of new media. Not that long ago, it would have been common to think that most young people would do the bulk of their composing in school, but this is rapidly changing. Writers are influenced by an audience of known or unknown readers. They write and create texts differently in these authentic situations. The shift of writing inside the affinity space has consequences for the writing process, including planning, motivation and metacognition (Magnifico, 2012). In traditional classrooms, the motivation to engage in writing comes primarily from the teacher students generally write for teachers in order to be assessed for their knowledge and skill. In the afterschool space the motivation comes from elsewhere. Writing in affinity spaces takes place within a community and is most often a tool for expression, creativity and communication. Writers within these spaces also receive audience feedback. Thomas (2008) reports that one of her research participants said, “... that within a week of posting a piece of fanfiction, she received over 100 responses of critical feedback about all aspects of her writing, from plot development to spelling” (p. 692).

Anna's participation in the DeviantArt.com affinity space represented demonstrates the sophisticated participatory medium, and the dynamic ecological system that the web has become as it provides rich opportunities for sharing and supports "multiple modes of learning" (Brown \& Adler, 2008, p. 18). Anna, in essence, brought her online social network into the project and all of those people had access to what Anna was doing in the research project. In describing in an interview what happens on DeviantArt.com Anna said,

The environment is very supportive. The majority of comments are pleasant unless you post something controversial, and the community looks forward to future posts. When I upload something to the website, I always receive a "welcome back" or "nice to see you" from other members. As well, even the more popular artists will generally answer questions you post on their art. For example, if someone creates an image and I want to know how they 
added text to it, they will either explain their method or send a link to a tutorial. Everyone always helps when asked. As well, DeviantArt now has its own chat room section where artists can talk about just about anything. The rooms are sectioned by topics, such as photography or a region. Individuals can even create their own rooms. Contests are held in many of these chat rooms. Others are for sharing your art, and some are just for moral support. If you are having a bad day and want to be cheered up, a quick stroll to the chat rooms will brighten your day.

Anna is describing a community of practice that is supportive, that provides mentorship, scaffolding, and it would seem, camaraderie. However, it must be noted that this is not always the case, and such support is not everyone's experience.

In preliminary research, I interviewed 11 fanfiction site users ranging in ages from 18 to 25 . Each described their experience of creating fanworks inside affinity spaces as generally a positive one. In responding to the question of what specifically was positive about the experience participants wrote,

It (writing in an affinity space) has helped in the growth of my literacy practices in that I was slowly able to improve my spelling, grammar etc., by constantly writing and having my online friends point out my mistakes, giving me constructive criticism, positive reinforcement/feedback etc.

My self-confidence and writing skills have grown. Through Tumblr, I have met friends from all over the world who I regularly talk with and we work together on projects. Polite criticism and advice have really inspired me to move out of my comfort zone and helped me progress as a writer.

I found that roleplaying (RP) on Tumblr has improved my literary skills. By having feedback from fellow RPers, I have found how I RP my characters, what needed to be improved on and what I did well.

With the rise of new media sites such as games and fanfiction communities, young people are no longer constrained to writing for teachers in traditional school settings. In new media, affinity spaces writers seek social connections with other users who are interested in the same kinds of activities and topics. Typical responses to the question asking what is positive about creating texts in online affinity spaces were:

I have met many, many friends through sharing my creations and seeing other's as well.

It's fun to connect with people that have the same interest as you!

It helped me meet amazing people, it helped me cope with my depression during the times I was seeing a therapist.

Communicating with others who share my interests on Tumblr and on FanFiction.net forums enabled me to meet a variety of interesting people, several of whom I'm proud to call best friends today.

However, in Canada and the United States, many traditional schools have responded to the shift towards social writing with fear, locking down social networks and blogs on school computers, forbidding the wide audience that comes with an internet that is 
open to a variety of writing topics and sites (Magnifico, 2012). Schools are struggling to find the balance and negotiate what these new technologies and media spaces mean for learning and for the development of children and youth. While much has been written about the potential of new media to radically transform learning, there may also be a sense by many that the new media boosterism is naively celebratory in the face or real concerns and dangers. Despite a unanimous overall positive response to their online text creation experiences, each participant was able to detail instances that were negative and would raise cause for some concern.

... I have received several hate messages for things I choose to draw (people that don't like who I pair characters with) but overall it doesn't affect me too much.

I used to get death threats for not liking some characters.

Being stalked by a person who roleplayed and wouldn't leave me alone, plus they were several years older than me.

Everyone has an opinion and if you don't agree you're harassed or worse. They will hate on you if you portray a character wrong.

Schools have legitimate concerns about safety, especially in the face of intensely media covered cases involving cyber harassment and the suicide of targeted victims. Also, recent reports have raised alarms about the amount of time young people spend on screen media (Jenkins, 2006). Without diminishing the concerns about lack of real world play spaces, the detrimental health affects, the moral values and commercial messages to which young people are exposed, the focus on such negative effects does not provide the complete picture.

\section{ESD and Teaching New Media Literacies}

It has been shown that the afterschool space is a dynamic and engaging environment for many young people where they are hard at work teaching themselves and others very important things that are relevant to them now and will be useful to them in the future. Traditional schooling must find ways to better align itself with what is already happening in students' informal educational lives. Young people require knowledge about how to negotiate the promise and the peril of participatory culture. Children and young people need adult supervision and guidance. They require the critical skills to articulate their experiences with new and emerging media practices. Schools must be instrumental in helping young people to develop the ethical norms and critical consciousness to deal with complex and diverse social environments online. The challenge of ESD pedagogies is to help bridge the gap that currently exists. The opportunities for rich learning to nurture the values of sustainability are too great to ignore. Jenkins (2006) states,

The new literacies almost all involve social skills developed through collaboration and networking. These skills build on the foundation of traditional literacy, research skills, technical skills and critical analysis skills taught in the classroom. (p. 29) 
Rather than attempt to control, constrain, shut down and ban opportunities for students' online engagement and social participation and by doing so exacerbate the sense of irrelevancy and disengagement of young people, schools must take on the challenge of integrating traditional literacy with new media literacies to promote the tenets of ESD.

\section{Ethics, Norms and Rules of the Affinity Space}

The potential for authentic learning and developing important skills, and creative, original ideas in affinity spaces is too great to simply ignore. These spaces have the possibility to help to foster thoughtful, engaged global citizens able to build creative networks, create new knowledge and take on complex problems, precisely what groups like the Waterloo Global Science Initiative (2014) and other forward thinking stakeholders in education espouse as an example of $21^{\text {st }}$ century learning. Young people are navigating these spaces with varying degrees of success. What they require are knowledgeable guides who can help them to understand the dynamics of these spaces and critically analyse their own involvement and the involvement of others. Henderson (2013) points to the need to critically examine participatory cultures and to see them as bounded by the rules of the culture. Students can be taught to ask who has the power to set topics of discussion and organise the contributions. And how are initiates inculcated into the culture of the space? What is the over-riding climate in the space? Finding spaces with clearly developed and articulated rules may be indicative of the future success of the online community. However, Henderson (2013) points out that "the rules of participation ... are not universal. Rules that govern online interaction, for example, posting, commenting, uploading, sharing, inviting, are unique to each participatory culture... Learning the rules for one certainly doesn't mean learning the rules for all" (p. 274). My preliminary research bears out the difficulty that can result when confusion over norms, rules and roles occurs.

One student wrote in response to a question about the level of support experienced within an online community:

\section{It started off fun and easy going but as time went on things just became more toxic. My co-administrator began pushing ideas into the universe I had created without consulting me first. I ran my own forum for about four years until my co-administrator pushed me too far, and we had to ban him.}

Students can be assisted to develop online social skills by being critically aware of how the spaces into which they venture may be organised and if the space is a good "fit" for them and their particular sensibilities. Students can be allowed to realise in a supportive manner that many affinity sites are governed by informal rules, and they may be vigorously enforced through public reprimand. Learning is happening in these spaces, but it may not be happening through positive or constructive feedback. As indicated in the comment above, control over input is wielded when the perception is that the rules and norms have been breached. The individual affront of "pushing me too far" was met with the communal response "we had to ban him". To meet an ethical standard of participation, rules must be developed by members, enforced fairly and taught consistently to new members. Without such adherence to ethical norms and rules, community groups eventually fail. 
Some respondents indicated knowledge of and a willingness to use, features of the online platforms they were using to control respondents and shape the environment to ensure a level of support with they felt comfortable.

For fanfiction.net, I can control whether or not people review anonymously by turning the option on or off. I can also delete anonymous reviews. On Tumblr, I can control who sends me asks, whether they can do it anonymously. I can control who sees my posts on Tumblr.

I have turned off the Anonymous message feature on Tumblr due to some hateful messages and occasionally turn off comments on DeviantArt.

More respondents, however, indicated they did not use these features at all. Teaching students to seek out the features designed to safeguard privacy and control hateful or harassing commentary provides another level of skilful use of the software.

Formal schooling and traditional schools must become the champions of ethics in the online participatory spaces being frequented by young people. Teaching young people to expect participants in their online communities to adhere to a high level of conduct that forbids taunting, mocking, threats, hateful belittling and harassment will allow online communities to reach their full potential and support the establishment of online spaces guided by a sense of equality, respect and tolerance. It is schools' moral obligation and pedagogical responsibility to the education and well-being of our children and youth to become engaged in the afterschool space and use it as a powerful tool to shape the next generation of digital and global citizens. ESD is perfectly positioned to provide the pedagogical framework through which such learning can take place. Kozak and Elliott (2014) provide learning strategies for developing a focus on sustainability and provide a context in which the content, skills, and ethics required for digital global citizenship could be realized. Those strategies

- link economic, social and environmental issues within subjects, between subjects and across all subjects;

- link students to each other, their home life, their school and their community (Kozak \& Elliott, 2014).

It is only by understanding young people's involvement in the afterschool space and making connections to the realities of the digital lives of students can we bring relevance to learning and provide the necessary skills the young require to thrive as global citizens. Education for sustainability is the catalyst that can provide a way forward for this challenging imperative.

\section{Acknowledgement}

This research was supported by the Social Sciences and Humanities Research Council (Government of Canada) through an Insight Development Grant.

\section{References}

Abrams, S., Gerber, H., \& Burgess, M. (2012). Digital worlds and shifting borders: Popular culture: Perception and pedagogy. In B. Williams \& A. Zenger (Eds.), New media literacies and participatory popular culture across borders (pp. 90105). New York: Routledge. 
Atwell, N. (1993). In the middle: New understandings about writing, reading and learning ( $2^{\text {nd }}$ ed.). Toronto, ON: Irwin Publishing.

Barrell, B., \& Hammett, R. (2002). Digital expressions: Media literacy and English language arts. Calgary, AB: Detselig Enterprises.

Brooks, M., \& Holmes, B. (2014). Equinox blueprint: Learning 2030 - a report on the outcomes of the Equinox summit. Waterloo, ON: Waterloo Global Science Initiative.

Brown, J., \& Adler, R. (2008). Minds on fire: Open education 2.0. Educause Review, 43(1), 17-32.

Buck, A. (2012). Examining digital literacy practices on social network sites. Research in the Teaching of English, 47(1), 9-38.

Burn, A., \& Nixon, H. (2005). English and the visual: From montage to manga. English Teaching: Theory and Practice, 4(1), 1-5.

DeVane, B. (2012). Whither membership? Identity and social learning in affinity spaces. In E. Hayes \& S. Duncan (Eds), Learning in video game affinity spaces (pp. 162 185). New York: Peter Lang.

Dobson, T., \& Willinsky, J. (2009). Digital literacy. In D. Olson \& N. Torrance (Eds.), The Cambridge handbook of literacy (pp. 286-312). New York: Cambridge University Press.

Doering, A., Beach, R., \& O’Brien, D. (2007). Infusing multimodal tools and digital literacies into an English education program. English Education, 40(1), 41-60.

Gee, J. (2004). Situated language and learning: A critique of traditional schooling. New York: Routledge.

Henderson, J. (2013). Toward an ethical framework for online participatory cultures. In A. Delwiche \& J. Henderson (Eds.), The participatory cultures handbook (pp. 272-280). New York: Routledge.

Hopkins, C. (2013). Education for sutainable development in formal education in Canada. In R. McKeown \& V. Nolet (Eds.), Schooling for sustainable development in Canada and the United States (pp. 23-37). New York: Springer.

Howard, P. (2014). Affinity spaces and ecologies of practice: Digital composing processes of pre-service English teachers. Language and Literacy - Canadian e-Journal, 16(4). http://ejournals.library.ualberta.ca/index.php/langandlit/issue/current

Jenkins, H. (2006). Confronting the challenges of participatory culture: Media education in the $21^{\text {st }}$ century. Retrieved from http://www.digitallearning.macfound.org/

Kozak, S., \& Elliott, S. (2014). Connecting the dots: Key strategies that transform learning for environmental education, citizenship and sustainability. Oshawa, ON: Maracle Press.

Knobel, M., \& Lankshear, C. (Eds.). (2007). A new literacies sampler. New York: Peter Lang.

Lankshear, C., \& Knobel, M. (2007). Sampling the "new" in new literacies. In M. Knobel \& C. Lankshear (Eds.), A new literacies sampler (pp. 1-24). New York: Peter Lang.

Magnifico, A. (2012). The game of neopian writing. In E. Hayes. \& S. Duncan (Eds.), Learning in video game affinity spaces (pp. 212-234). New York: Peter Lang.

Mills, K. (2010). A review of the digital turn in the new literacy studies. Review of Education Research, 80(2), 246-271. 
Prensky, M. (2010). Teaching digital natives: Partnering for real change. Thousand Oaks, CA: Corwin.

Robertson, L., Hughes, J., \& Smith, S. (2012). Thanks for the assignment! Digital stories as a form of reflective practice. Retrieved from ejournals.library.ualberta.ca/ index.php/article/view/1678

Soven, M. (1999). Teaching writing in middle and secondary school: Theory, research and practice. Boston, MA: Allyn and Bacon.

Swenson, J., Rozema, R., Young, C., McGrail, E., \& Whitin, P. (2006). Beliefs about technology and the preparation of English teachers: Beginning the conversation. Contemporary Issues in Technology and Teacher Education, 5(3/4), 351-369.

Thomas, A. (2008). Community, culture and citizens in cyberspace. In J. Coiro, M. Knobel, C. Lankshear \& D. Leu (Eds.), Handbook of research on new literacies (pp. 671-697). New York: Routledge.

Waterloo Global Science Initiative. (2014). Equinox blueprint learning 2030. Kitchener, ON: University of Waterloo.

Correspondence concerning this paper should be addressed to Patrick Howard, Associate Professor, Cape Breton University, Sydney, Nova Scotia, Canada B1P 6L2. Email: patrick_howard@cbu.ca 